\title{
Readiness of local government in PPP project development - case of LRT Bandung
}

\author{
Revana Putri ${ }^{1}$ and Reini D. Wirahadikusumah ${ }^{2, *}$ \\ ${ }^{1}$ Magister Study Program of Civil Engineering, faculty of Civil and Environmental Engneering, Institut Teknologi Bandung, Bandung, \\ Indonesia \\ ${ }^{2}$ Construction Engineering and Management Research Group, Faculty of Civil and Environmental Engineering, Institut Teknologi \\ Bandung, Bandung, Indonesia
}

\begin{abstract}
Infrastructure development with PPP (Public Private Partnership) scheme is a relatively new concept applied by the Indonesian construction industry as an alternative to overcome delays and the low absorption of the Indonesian Government Budget (APBN) and Regional Government Budget $(A P B D)$ in the procurement of basic infrastructure. However, in practice, the failure rate of the government in carrying out infrastructure projects with PPP scheme is high. The failure of PPP project is generally caused by the way the government works in preparing projects that are not adjusted to the needs of PPP, the constraints of land acquisition, poor coordination between central and local government, participation, and overlapping regulations. This raises the question of how to know the condition of government readiness in implementing projects under PPP scheme and identify the constraints affecting government readiness. This study develops an assessment that can be used to measure government readiness in implementing projects under PPP scheme. Factors used in the system were developed based on three studies on the readiness assessment systems in various countries, namely: Public-Private Partnerships for Transport Infrastructure Toolkit from PPPIRC World Bank, United Nations Economic and Social Commission for Asia and the Pacific (ESCAP) and United Nations Economic Commission for Europe (UNECE). The assessment will be used to assess the level of readiness and constraints faced by the government of Bandung in implementing the project LRT Bandung.
\end{abstract}

\section{Introduction}

As time goes by, the need for various infrastructure facilities support is increasing. However, the delay and low absorption of capital expenditures both national and regional ( $A P B N$ and $A P B D)$, as well as limited funds, and many other government priorities become obstacles in the procurement of basic infrastructure. Therefore, the government needs to find a breakthrough in terms of obligations to provide basic infrastructure and facilities. The scheme of Public-Private Partnership (PPP) is one of the alternative solutions.

Transportation infrastructure that is expected to always grow better in Indonesia even has a worrisome condition. Indonesia is still lagging behind in the development and provision of transportation infrastructures such as railways, road networks, ports, and airports. This condition occurred for almost the past 20 years or since the economic crisis of 1997/1998 to the current era, when compared to other countries or neighbor countries such as Malaysia (source: PPP Guidelines, PT SMI, 2014). The government considers this condition is caused by the problem of low allocation for infrastructure especially transportation infrastructure. Due to the low allocation of expenditure, the construction of infrastructure is slow, even the allocation of development funds is diverted into the cost of maintaining the infrastructure which should not be required if the infrastructure is built properly. In practice, projects with the PPP scheme often face problems such as the high cost of tendering, complex negotiation, and different opinion that arise conflicts among stakeholders (source: Akintoye, et al 2001). The failure rate of Indonesian government in building infrastructure projects is relatively high.The failure of PPP project is generally caused by the way the government works in preparing projects that are not adjusted to the needs of the PPP, the constraints of land acquisition, poor coordination between central and local government, the regional People's Representative Council (DPRD) participation, and overlapping regulations. Infrastructure development is an obligation of local and central government and aims to serve the community. The government's lack of preparation can cause adverse effects such as project delays or failures. The readiness of the government plays a major role in realizing the success of the project under the scheme of

\footnotetext{
* Corresponding author: reiniwhk@gmail.com
} 
PPP. This research will develop factors of government readiness assessment for transportation infrastructure project with the scheme of PPP. Then, the results will be compared to the condition of the government's readiness for LRT development project in Bandung.

\section{Literature Review}

\subsection{Public-Private Partnership (PPP)}

PPP could be defined as a long-term contract between the Government and the Business Entity in the case of provision of public infrastructure or services. PPP arrangements are useful for large projects that require highly-skilled workers and a significant cash outlay to get started. They are also useful in countries that require the state to legally own any infrastructure that serves the public. The use of PPP scheme as an alternative in the provision of infrastructure is expected to be a solution and to overcome these challenges. In general, the concepts of PPP are described in Table 1.

The challenges faced by the government in infrastructure development with the scheme of PPP are:

1. Insufficient funding

2. Improper project planning and selection.

3. Inefficient management.

4. Inadequate maintenance

Table 1. PPP concept

\begin{tabular}{|l|l|}
\hline \multicolumn{2}{|c|}{ PPP Concept } \\
\hline Cooperation & $\begin{array}{l}\text { Cooperation that makes mutual } \\
\text { benefit between Government, Private, } \\
\text { and Society. }\end{array}$ \\
\hline Asset & Owned by the Government \\
\hline Risk & Sharing \\
\hline $\begin{array}{l}\text { The Role of } \\
\text { Government }\end{array}$ & $\begin{array}{l}\text { Facilitator/ payment for services } \\
\text { provided by the private sector. }\end{array}$ \\
\hline
\end{tabular}

(Source: PPP Guidelines, PT SMI, 2014)

\subsection{Developing government "readiness" assessment system}

PPP scheme has been applied in other countries since fifty years ago. Portugal and the UK apply the PPP scheme for Toll Roads, while the Netherlands, America, and Japan apply it for other infrastructures such as Government Office Buildings, Schools, Prisons, Hospitals, Police Dormitories, and so on. Principles that are fundamentally used in PPP scheme are Effectiveness and Cost Efficiency, Risk Transfer to Private, and Value for Money.

\subsubsection{Definition of government readiness}

The definition of readiness in this study is conditions which indicate that the government has met the factors of the Readiness Assessment System in carrying out PPP in a transportation project. The government readiness assessment used in this research is formulated from the guidance of the implementation of the PPP in Indonesia, and the formulation of several assessment systems that have been used in other countries as described above. The government's readiness assessment system was developed using these standards:

1. Readiness Assessment Standard of LRMT with PPP scheme made by PPPIRC World Bank.

2. Standards of Readiness Assessment made by United Nations ESCAP.

3. Standards of Readiness Assessment of PPP Project according to UNECE.

From several standards of government readiness we can't immediately implement it. Factors must be selected from those standards, to see conformity with conditions in Indonesia. Assessment will be identified by some appropriate parameters that can be used as an assessment factor to determine the level of readiness of Indonesian government and by considering some additional factors obtained from the Toolkit of PPP made by BAPPENAS. The factors are Conformity of the cooperation project with national Medium-Term Development Plan/ Ministry Strategic Planning, Local Government Work Plan, and Business Plan of States Owned Companies.

\subsubsection{PPP toolkit by Indonesian Ministry of National Development Planning (BAPPENAS)}

The PPP regulatory toolkit in Indonesia contains factors of what should be done by the government to comply with every stage of the PPP implementation. The PPP toolkit is regulated by Presidential Regulation No. 67 of 2005, which was changed to Presidential Regulation No.13 of 2010, and then updated again to Presidential Regulation No.38 of 2015.

\subsubsection{Readiness assessment standard of LMRT with PPP scheme by PPPIRC Word Bank}

In a book entitled Private Sector Participation in Light Rail-Light Metro Transit Initiatives by Cledan MandriPerrott, an effective LRT system implementation toolkit has been developed based on the best practices of LRT implementation in various countries under the PPP scheme. In general, the standard criteria of government's readiness in implementing LRT projects under the PPPIRC World Bank Transportation Infrastructure Toolkit include 6 areas, they are Private Sector Participation in LRT, LRT Risk Management, Design, Specification and Performance of PPP Schemes, Financial Management, Contract Management, and Procurement. This assessment standard would be used to develop new assessment standard in Risk Management and Contract Area.

\subsubsection{Readiness assessment standard of LMRT with PPP scheme by United Nations ESCAP}

The United Nations Economic and Social Commission for Asia and the Pacific (ESCAP) is an organization that supports governments in Asia-Pacific in implementing efficient factors to involve private sectors in infrastructure development. This assessment system can be used to 
determine the main problems that occur in the project's implementation using the PPP scheme. Standard criteria for government readiness implementing LRT projects based on United Nations ESCAP divided into 5 areas: Background PPP, Social and political policy framework, legal framework, procurement capacity and the process of implementation of the PPP. This assessment standard would be used to develop new assessment standard in Regulation and Policy Area.

\subsubsection{Readiness assessment standard of LMRT with PPP scheme by UNECE}

The United Nations Economic and Social Commission for Europe (UNECE) is an organization to set norms, standards, and conventions to establish International cooperation within and outside the European region. The standard criteria for government readiness measures for implementing LRT projects under UNECE cover 7 areas: Governmental conditions, government policies, capacity building, regulatory capacity, sustainable construction, project management, and finance. This assessment standard would be used to develop new assessment standard in Regulation related to finance and sustainability of the project.

\section{Research method}

In assessing the level of government readiness, it is necessary to develop a readiness assessment system. The initial formulation of the readiness assessment system was developed based on a literature study and preliminary analysis of the readiness assessment factor. The development of the formulation of the readiness assessment system will be further matured by testing the relevance of the appropriate factors, and it can be used in assessing the level of readiness of the government in Indonesia in the expert's opinion. Flowchart of this research method can be seen in Figure 1.

\section{Development of the assessment system}

\subsection{Government readiness}

Availability of good quality infrastructure is one of the determinants of a region/country's attractiveness. The strategic role of infrastructure is also demonstrated by various empirical studies which state that better infrastructure availability will contribute to the increase in economic growth. Public-Private Partnership is one of the alternative schemes that are expected to provide more efficient infrastructure services in order to meet the transportation infrastructure needs in Indonesia.

Government's lack of preparation can cause adverse effects such as delays or project failures. This readiness assessment system is intended to provide an overview of the government's conditions in the implementation of infrastructure projects under the PPP scheme in Indonesia.

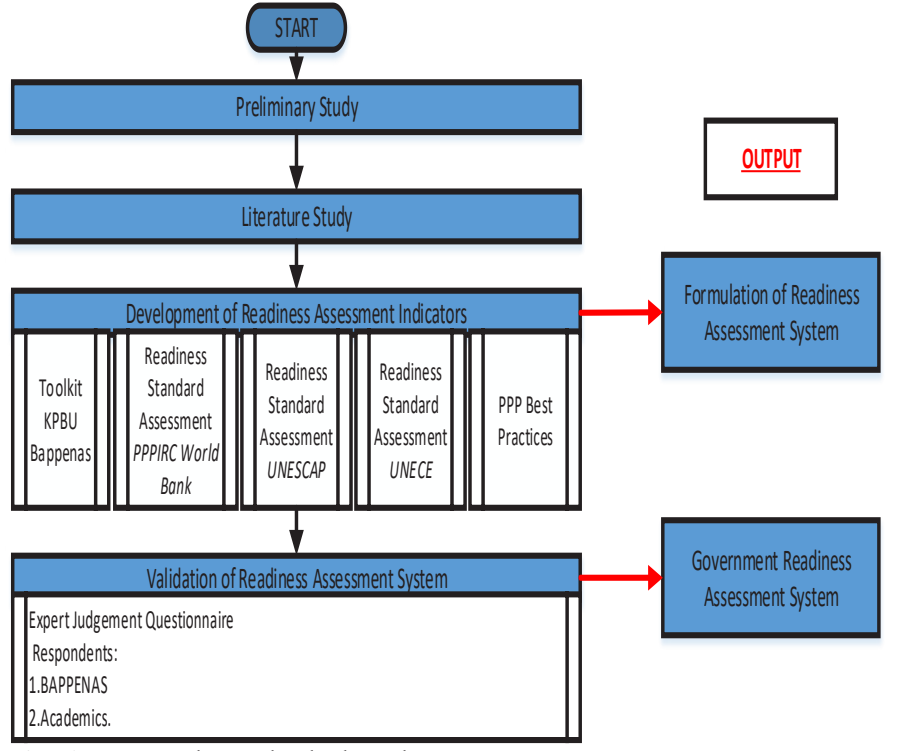

Fig. 1. Research Method Flowchart

\subsection{Developing the factors of assessment}

The first step in developing this assessment system is to analyse which areas can be used to assess the government's readiness in implementing projects under the PPP scheme in Indonesia. Using three studies previously presented, which mentioned readiness assessment systems in various countries and adapted to the BAPPENAS toolkit. Based on the data, we mapped nine areas that describe the composite of all areas of the system.

These areas will then be used as the first level (hierarchy) grouping of the readiness assessment system. The next step in this study is to map more deeply to the factors that will be identified into the system for each area. These factors are adopted from the scoring system mentioned above. The nine areas of scope selected as part of this readiness system formulation can be seen in Table 2 .

\subsection{System relevance test}

After identifying the assessment factors, the formulation of the readiness assessment system will be further matured by testing the relevance factors based on expert's opinion. The relevance test was conducted by using questionnaires as well as structured interviews to gain the perception of expert judgment. Respondents in this relevance test are BAPPENAS and Academician of Institute Technology Bandung. Assessment of relevance will tend to be subjective and highly dependent on the expertise and previous experience of respondents in PPP project.

Nevertheless, the selection of the respondents of this research is done in such a way that it is expected to represent the results of the assessment of the government's readiness system. In the relevance test, respondents were asked to fill the relevance of the system with Yes (Y) or No $(T)$ in the relevance $(R)$ column. Respondents were also asked to provide information and/or improvement suggestions for the system. 


\subsection{Government Readiness Assessment System}

From the relevance testing process, it can be identified that there are twenty-two (22) factors from 9 areas of the government's readiness assessment system (See Table 2) that can be said to be relevant. These factors will then be used as part of the government's readiness assessment system in infrastructure projects under the PPP scheme. Assessment variables on these factors are derived from how the government implementing the things stated in the factors itself.

This readiness assessment system will be filled by heads of strategic units and government policies (or equivalents). In collecting data to assess readiness, the five-point Likert scale was used to obtain the respondent's description. The assessment size that can be given for each question is with the following conditions:

1. Not Good: No implementation plan related to the factor.

2. Less Good: There are implementation plans related to the factor but not yet implemented.

3. Medium: Implementation of related factors has been implemented but not yet good and still not consistent.

4. Good: Implementation of related factors has been implemented well but not yet consistent.

5. Very Good: Implementation of related factors has been implemented well and has been consistent.

Consistent in this assessment means that, the factors and standards have been implemented thoroughly. After the relevance system test based on expert opinion, the selection of factors used in this readiness assessment system can be used as respondents. The relevant parties that can be the respondent are all the PPP stakeholders, such as BAPPENAS Regulation are PPP Project Officials; PPP Node; PPP Setup Agency; Technical Team of PPP and Procurement Committee. Selected factors will be asked to the relevant parties, in hope of getting answers on the more accurate implementation of existing factors.

Tabel 2. Government Readiness Assessment System

\begin{tabular}{|c|l|}
\hline $\begin{array}{c}\text { AREA } \\
\mathbf{1}\end{array}$ & \multicolumn{1}{|c|}{ Related Factor } \\
\hline 1.1 & Government's Support \\
\hline 1.2 & Public Participation \\
\hline 1.3 & Law Enforcement Conditions \\
\hline $\begin{array}{c}\text { AREA } \\
\mathbf{2}\end{array}$ & \multicolumn{1}{|c|}{ GOVERNMENT POLICY } \\
\hline 2.1 & $\begin{array}{l}\text { Consistency and Clarity of Policies } \\
\text { Related to PPP }\end{array}$ \\
\hline 2.2 & Content of PPP Policy \\
\hline 2.3 & Business Entity \\
\hline $\begin{array}{c}\text { AREA } \\
\mathbf{3}\end{array}$ & \multicolumn{1}{|c|}{ GOVERNMENT'S CAPACITY } \\
\hline 3.1 & The conditions of government capacity \\
\hline 3.2 & $\begin{array}{l}\text { Government Development Program related } \\
\text { to PPP }\end{array}$ \\
\hline $\begin{array}{c}\text { AREA } \\
\mathbf{4}\end{array}$ & REGULATION \\
\hline 4.1 & $\begin{array}{l}\text { A clear legal basis for PPP project } \\
\text { implementation. }\end{array}$ \\
\hline
\end{tabular}

\begin{tabular}{|l|l|}
\hline 4.2 & \multicolumn{1}{|c|}{ Related Factor } \\
\hline $\begin{array}{c}\text { AREA } \\
\mathbf{5}\end{array}$ & PPP CONTRACT MANAGEMENT \\
\hline 5.1 & $\begin{array}{l}\text { General Framework of Investment } \\
\text { Contract }\end{array}$ \\
\hline 5.2 & Development related provisions \\
\hline $\begin{array}{c}\text { AREA } \\
\mathbf{6}\end{array}$ & SUSTAINABLE DEVELOPMENT \\
\hline $\begin{array}{l}6.1 \\
6.2\end{array}$ & $\begin{array}{l}\text { Environmental Policies and Regulations } \\
\text { planning }\end{array}$ \\
\hline $\begin{array}{c}\text { AREA } \\
\mathbf{7}\end{array}$ & \multicolumn{1}{|c|}{ PROJECT MANAGEMENT } \\
\hline 7.1 & Project Management Process \\
\hline 7.2 & Basic Capabilities of Project Management \\
\hline 7.3 & $\begin{array}{c}\text { Design Conditions and Specifications of } \\
\text { PPP Projects }\end{array}$ \\
\hline 7.4 & Risk Allocation \\
\hline $\begin{array}{c}\text { AREA } \\
\mathbf{8}\end{array}$ & PROJECT PROCUREMENT \\
\hline 8.1 & Procurement Management Team \\
\hline 8.2 & $\begin{array}{l}\text { Condition of the Method of Selection and } \\
\text { Evaluation of the Proposal }\end{array}$ \\
\hline $\begin{array}{c}\text { AREA } \\
\mathbf{9}\end{array}$ & FINANCIAL \\
\hline 9.1 & Condition of Financial Structure \\
\hline 9.2 & PPP Project Financing. \\
\hline
\end{tabular}

\subsection{Assessment of government readiness system}

To implement a comparison of the readiness, scaling is made in the form of government readiness levels in project implementation under the PPP scheme. The scaling of this readiness assessment system refers to two quantitative rating scales that have been widely used by other studies on readiness assessment in Indonesia. It can determine the readiness level group of this readiness assessment model, they are:

1. Not ready to implement the project with the scheme PPP, for readiness value below 50 .

2. Tend to be ready to carry out projects under the PPP scheme, for readiness values equal to and above 50 .

In collecting data to assess readiness, a Likert scale of 5 (five-point Likert scale) is used to obtain a readiness picture in which each factor is measured in its implementation level. Measurements using this Likert scale are independent.

Then, as described in the previous chapter, to interpret the value of readiness obtained from the calculation of the readiness assessment system, scaling is done in the form of project preparation level under the PPP scheme.

Table 3. Determination of Weight Scale from Factor Implementation Level

\begin{tabular}{|c|c|}
\hline Variable & Score \\
\hline No Good & 0 \\
\hline Less Good & 1 \\
\hline
\end{tabular}




\begin{tabular}{|c|c|}
\hline Variable & Score \\
\hline Medium & 2 \\
\hline Good & 3 \\
\hline Very Good & 4 \\
\hline
\end{tabular}

Determination of the weight scale from the level of implementation of the factor is in Table 3. Then the result of the readiness value of each factor is converted into a percentage by using the formula below:

\section{(Total value per factor / total maximum value) $x 100 \%$}

The percentage result of each factor then changed to the percentage result of each area with the average method. The calculation by the same method is also used to change the percentage of each assessment area into the percentage of the system assessment results' overall value.

\subsection{The Result of the assessment system in LRT Bandung case}

The results of the development of this scoring system can be seen in Table 2, comprising nine areas of the readiness assessment system. This system conducted a test of readiness assessment system against the Government of Bandung in implementing LRT Bandung Raya project. The test results conclude several things as follows:

1. The Government of Bandung City in LRT project, which becomes respondent from this research on average (overall) area, has a value of readiness of project implementation with the scheme of PPP equal to $59.1 \%$. This readiness value is categorized as "medium". This shows that the Government of Bandung City needs to make improvements in order to further optimize the implementation of transportation infrastructure projects with PPP scheme in the future.

2. From the results of the analysis, the Government Policy area gets the highest average readiness score of $73.6 \%$, while the financial area gets the lowest value of $43.75 \%$. Further explanation of the analysis result and obstacle faced by the Government of Bandung City from each area are as follows:

- Analysis Results of Area 1:

The overall Government Condition received a "good" score with an average readiness rate of $70.8 \%$. However, there are factors that need to be paid attention by the government in this area, namely the support factor for using the PPP. This factor received the lowest level of readiness of $37.5 \%$. This is because the LRT Bandung project and other PPP projects are very difficult to get support from $D P R D$, the multiparty system in Indonesia causes no guarantee of budget availability in case of policy alteration when the head of region is changed.

- Analysis Results of Area 2:

The overall Government Policy scored "good" with the highest average readiness rate of $73.8 \%$. However, there are factors that need to be considered by the government in this area, namely the contents factor of the PPP. This factor gets the lowest readiness level that is equal to $54.2 \%$. This is because there is no special policy from the local government to deal with the problems that may arise during the implementation of the project under the PPP scheme.

- Analysis Results of Area 3:

Overall Government Capacity scored "medium" with an average readiness level of $50 \%$. This area needs special attention from the local government. The condition factor of institutional readiness in this area only gets the value of readiness of $37.5 \%$. This is because the government does not have sufficient resources and adequate technical certification. The condition of the institutional capacity of the project with the PPP scheme in Bandung still needs to be improved and developed again so that the project implementation can run well.

- Analysis Results of Area 4:

The overall Regulatory Framework scored "good" with an average readiness rate of $62.5 \%$. There are factors that need to be paid attention by the government in this area, which is the factor of legal issues related to PPP. This factor only gets $50 \%$ readiness score. This is because the Government of Bandung is still having difficulties in implementing the central regulation of PPP. The PPP-related regulation is still only a general direction, while its technical direction is still very small. The municipal government sometimes finds it difficult to develop a technical implementation of the central government's general direction. Mistakes of interpretation are still common and sometimes inhibit the implementation of the PPP project

- Analysis Results of Area 5:

Overall contract arrangement scored "medium" with an average readiness rate of $58.3 \%$. The general framework of investment contracts and related provisions of development on the draft LRT contract still need many additional rules such as the mechanism of contract termination and dispute resolution, as well as conditions of protection against changes of law so that problems will not occur in the future.

- Analysis results of Area 6:

Sustainable Development analysis as a whole earned a "medium" score with an average readiness rate of $54.2 \%$. This area needs attention from the government, especially on the factor of sustainability implementation in the planning of infrastructure projects that only get the value of readiness of $33.3 \%$. The sustainable concept is still relatively new in Bandung. This concept has not been seen comprehensively and implemented in development.

- Analysis results of Area 7:

Project Management analysis overall got a "medium" score with an average readiness level of $47.1 \%$. There are several factors that have a very low readiness value that is the basic ability factor of project management and project management 
process. Lacks of technical team experience and coordination between poor technical teams have a significant impact on the late completion of the LRT project. Lack of coordination between these technical teams can lead to slow decision-making when problems occur and the completion process will be long.

- Analysis results of Area 8:

Project Procurement analysis overall got a "good" score with an average readiness rate of $71.9 \%$. The things that need to be considered by the government in this area is the regulation related to the procurement of PPP, which is still need to be adjusted to the local condition so that there is no arrangement problems with the regulation of the area.

- Analysis results of Area 9:

Financial analysis as a whole scored "medium" with the lowest average readiness level of $43.75 \%$. This area needs special attention from the local government. The financial capacity of Bandung City Government to pay for expenses such as land acquisition, re-financing, and start-up, is not good. The LRT project does not get funding support from the central government. Bandung City Government also has not done the project financing plan well. The financing plans are incomplete and there are some unexpected analyses, such as the Transit Oriented Development (TOD) area analysis and the financing scheme without government support. As a result, the payback plan has not been properly implemented.

\section{Conclusion and suggestions}

\subsection{Conclusion}

1. The research on the development of this readiness assessment system resulted in the assessment system can be used to assess the readiness of local governments in implementing the transport infrastructure projects under the PPP scheme. The assessment system was developed based on three (3) studies on readiness assessment system in various countries, namely: Public-Private Partnerships for Transport Infrastructure Toolkit from PPPIRC World Bank, United Nations ESCAP and UNECE.

2. The system is then adapted to the guidance of the implementation stages of the transportation infrastructure development with the scheme of PPP in Indonesia by 4BAPPENAS. The results of the development of this scoring system can be seen in Table 2, comprising the nine (9) areas of the readiness assessment system and composed of twenty-two (22) factors.

3. From the study regarding the government readiness on LRT Bandung, it shows that the average of the area reviewed in this study has a readiness level of $59.1 \%$ in implementing the project under the PPP scheme, the highest level of readiness is the area of government policy with a value of $73.6 \%$, while the lowest value is the financial area which is $43.75 \%$.

\subsection{Suggestion}

1. Factors of assessment in this system were only done limited to interviews with respondents, literature studies, and document review available to the public. In some factors, actual document verification cannot be performed to assess whether the PPP implementation readiness factor is properly implemented or not and to what extent its effectiveness is implemented. This is due to limited access to data collection. Further development of this system can be done by referring to it.

2. The weight/importance level of each factor in this system is considered to be of equal value. There are biases, related to the results of the government's readiness assessment. The importance of each area may have different weights when compared to the impact of readiness. Further development of this system can be done by referring to it. Determination of the weight of each factor on this system can be done with the help of expert opinion. The readiness assessment system generated in this research is only through a simple validation process with the assessment of academics and BAPPENAS due to the limited time of research. Further research can validate the other parties who are more experienced in implementing the project with PPP scheme in order to have a more valid system improvement suggestion.

\section{References}

1. Stages of implementation of PPP from BAPPENAS, data obtained by internet site: http://toolkitPPPindonesia.com/index.html. Downloaded on October 27 (2016)

2. General data of Bandung Raya LRT Project, data obtained by internet site: http://lrt.bandung.go.id. Downloaded on October 1 (2016)

3. UNESCAP, Transport and Tourism Division. PublicPrivate Partnerships Readiness Tools Assessment in Infrastructure Development, Document. (2007)

4. The World Bank Group, The OECD. Project Checklist for Public-Private Partnership (2015)

5. The World Bank Group, Country Readiness Diagnostic for Public Private Partnerships, Document (2016)

6. Indicator of the government's readiness assessment system by PPPIRC Worldbank, data obtained by internet website: https://ppp.worldbank.org/publicprivate-partnership/. Downloaded on November 27, (2016)

7. The indicator of the government's readiness assessment system by UNECE, the data obtained bythe website https://www.unece.org/ceci/ppp.html. Downloaded on November 29 (2016) 